\title{
Hallazgos mediante microscopía confocal en trasplante endotelial mediante DSAEK
}

\author{
Confocal microscopy findings after endothelial transplant by DSAEK
}

Manuel Ramírez*, Claudia Ortiz, Guillermo Dewit-Carter y Everardo Hernández-Quintela

Departamento de Córnea y Cirugía Refractiva, Asociación para Evitar la Ceguera en México, Hospital Luis Sánchez Bulnes, Universidad Nacional Autónoma de México, Ciudad de México, México

\begin{abstract}
Resumen
Objetivo: Evaluar los hallazgos cicatriciales tempranos en la córnea de pacientes operados de DSAEK (Descemet's Stripping Automated Endothelial Keratoplasty) mediante microscopía confocal in vivo. Método: Se incluyeron 15 ojos de 15 pacientes. Se realizó microscopía confocal (Confoscan 4, Fortune Technologies, Italy) entre las 4 y las 7 semanas después de la cirugía de DSAEK. Las mediciones se realizaron desde el endotelio al epitelio corneal utilizando el programa Navis ${ }^{\circledR}$ software (NIDEK, Multi-Instrument Diagnostic System, Japan). Resultados: La interface donador-receptor se encontró a $114 \pm 12.4$ micras en promedio. Se comenzaron a observar pliegues en el estroma a $111.1 \pm 3.5$ micras desde el endotelio corneal hasta $286 \pm 94$ micras (promedio de $175 \pm 90.5$ micras del estroma corneal). Se comenzó a observar activación de queratocitos en el tejido donador a $12 \pm 1.4$ micras desde el endotelio hasta $105 \pm 38.2$ micras (promedio de $93 \pm 36.9$ micras del estroma corneal). Conclusiones: Los queratocitos del tejido donador se encontraron activados hasta 7 semanas después de la cirugía de DSAEK. En la proximidad de la interface donador-receptor se encontraron grandes pliegues en el estroma después de cirugía de DSAEK. Se requieren futuras evaluaciones para determinar la significancia clínica de estos hallazgos.
\end{abstract}

PALABRAS CLAVE: Confocal. Endotelial. DSAEK. Trasplante. Queratocito.

\begin{abstract}
Objective: To evaluate early in vivo corneal wound healing findings after Descemet's Stripping Automated Endothelial Keratoplasty (DSAEK) by using in vivo confocal microscopy. Method: $A$ total of 15 eyes of 15 patients were included. In vivo confocal microscopy (Confoscan 4, Fortune Technologies, Italy) was performed from 4 to 7 weeks after DSAEK. Measurements were scanned from the corneal endothelium to the corneal surface with a Navis ${ }^{\circledR}$ software (NIDEK, Multi-Instrument Diagnostic System, Japan). Results: Donor-receptor interface was found in an average of $114 \pm 12.4$ microns. Corneal stromal folds were observed from $111.1 \pm 3.5$ microns from the endothelium to $286 \pm 94$ microns (mean $175 \pm 90.5$ microns of the corneal stroma). Keratocites were activated in the donor tissue from $12 \pm 1.4$ microns from the endothelium to $105 \pm 38.2$ microns (mean $93 \pm 36.9$ microns of the corneal stroma). Conclusions: Donor keratocites are activated up to 7 weeks after DSAEK. Several corneal folds are present in proximity to the donor-receptor interface after DSAEK. Further evaluation of these findings is justified to determine its clinical significance
\end{abstract}

KEY WORDS: Confocal. Endothelial. DSAEK. Interface. Transplant. Keratocyte.

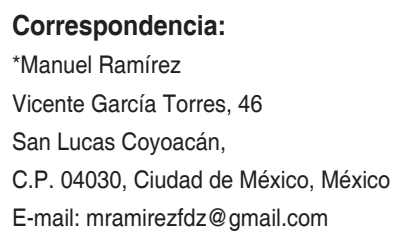

Fecha de recepción: 11-11-2017

Fecha de aceptación: 14-02-2018 DOI: $10.24875 /$ CIRU.M18000020
Cir Cir. 2018;86:128-131

Contents available at PubMed www.cirugiaycirujanos.com 


\section{Introducción}

El trasplante endotelial mediante la técnica DSAEK (Descemet's Stripping Automated Endothelial Keratoplasty) ha demostrado ser una buena alternativa quirúrgica para resolver las patología corneales en las que se encuentra dañado el endotelio corneal, con el estroma corneal respetado, y se requiere un injerto donador para la resolución del problema ${ }^{1,2}$. Así mismo, se ha reportado como opción en el tratamiento de pacientes que presentaron falla después de una queratoplastia penetrante ${ }^{3}$.

El propósito del presente estudio es evaluar los hallazgos cicatriciales tempranos de la córnea en pacientes operados de DSAEK mediante microscopía confocal in vivo.

\section{Método}

Quince ojos de 15 pacientes fueron sometidos a trasplante de endotelio corneal mediante la técnica de DSAEK ${ }^{2}$. Todos los injertos endoteliales se obtuvieron bajo pedido al banco de ojos, de un espesor de 100 micras cada uno. Los diagnósticos preoperatorios de los pacientes sometidos a cirugía de DSAEK fueron nueve queratoplastias bullosas secundarias a pseudofaquia y seis distrofias de Fuchs, también pseudofacos. El promedio de edad fue de $72.1 \pm 4.9$ años (rango de 63 a 76 años). Siete pacientes fueron del sexo masculino y ocho del sexo femenino.

Se realizó examen de microscopía confocal in vivo a todas las córneas de los pacientes, dependiendo de la transparencia corneal entre las 4 y las 7 semanas después del procedimiento de DSAEK mediante el uso del microscopio confocal de hendidura (Confisca 4; Fortune Technologies, Vigonza, Italy). En cada examen de microscopía confocal se obtuvo una secuencia de imágenes digitalizadas que constaba de cuatro rastreos consecutivos de la profundidad total del espesor corneal, siendo un rastreo equivalente a la obtención de imágenes de endotelio a epitelio y nuevamente a endotelio, es decir, de lo posterior a lo anterior y de nuevo a lo posterior, para permitir el desplazamiento en el eje $Z$ del espesor corneal central. Se utilizó el dispositivo de anillo Z (Confoscan, Fortune Technologies, Italy), el cual mantiene el contacto con la córnea para así poder obtener mediciones de espesor confiables sin tener movimiento anteroposterior del globo ocular.
Las imágenes fueron capturadas automáticamente en el disco duro de una computadora. Las mediciones se realizaron desde el endotelio hacia el epitelio corneal mediante el uso del programa Navis v. 3.5.0. (NIDEK, Multi-Instrument Diagnostic System, Japan).

\section{Resultados}

La transparencia corneal se observó entre las 4 y las 7 semanas después de la cirugía de DSAEK en todas las córneas operadas. La capacidad visual fue de 20/50 o más en todos los pacientes 7 semanas después del procedimiento.

La interface donador-receptor se encontró debido a la presencia de partículas hiperreflécticas a $114 \pm$ 12.4 micras (desde el endotelio al epitelio) en promedio (Fig. 1). Se comenzaron a observar pliegues en el estroma a $111.1 \pm 3.5$ micras desde el endotelio corneal hasta $286 \pm 94$ micras en dirección hacia el epitelio corneal (promedio de $175 \pm 90.5$ micras de espesor de estroma, con presencia de pliegues) (Fig. 2). Se comenzó a observar activación de queratocitos en el tejido donador a $12 \pm 1.4$ micras desde el endotelio hasta $105 \pm 38.2$ micras en dirección hacia el epitelio corneal (promedio de $93 \pm 36.9$ micras de espesor de estroma, con activación de queratocitos) (Fig. 3).

\section{Discusión}

El trasplante endotelial es una técnica que está tomando un lugar importante en los recursos quirúrgicos para el tratamiento de patologías corneales en las que la única estructura dañada es el endotelio corneal y, por ende, no es necesario el remplazo de toda la córnea, como en el caso de la queratoplastia penetrante ${ }^{2,4}$. Inclusive, la técnica de DSAEK ha demostrado su eficacia en el manejo de fallas primarias en queratoplastias penetrantes ${ }^{3}$. Así mismo, se han reportado resultados favorables en cuanto a agudeza visual y satisfacción posoperatoria de los pacientes sometidos a trasplante endotelial con técnica de DSAEK ${ }^{1,5}$.

En el presente estudio se valoraron los cambios cicatriciales tempranos in vivo en el tejido corneal después de una cirugía de DSAEK. La microscopía confocal se realizó hasta que se tuviera una transparencia adecuada en cada una de las córneas operadas, para que las imágenes de las diferentes estructuras de estas fueran valorables adecuadamente, así como poder realizar las mediciones de espesores de forma confiable sin la presencia de edema corneal. 


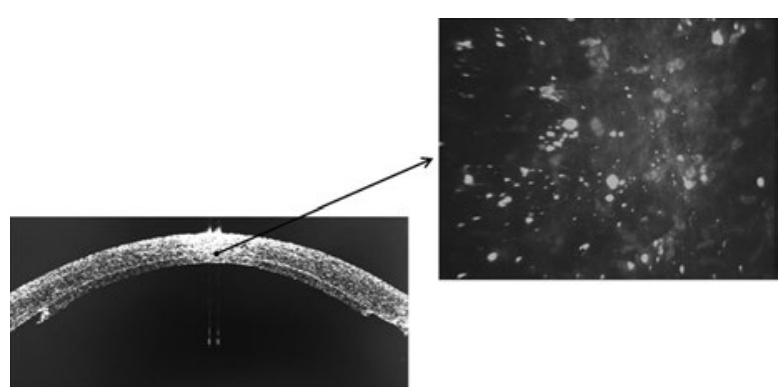

Figura 1. Imagen de microscopía confocal del estroma de la córnea (derecha) en la que se observa la presencia de partículas en la interface donador-receptor a $114 \pm 12.4$ micras desde el endotelio hacia el epitelio de la córnea $(340 \times 255 \mu \mathrm{m})$. Así mismo, se presenta una imagen de tomografía de coherencia óptica (izquierda) del mismo paciente; la flecha es para ilustrar que se trata de la interface donador-receptor.

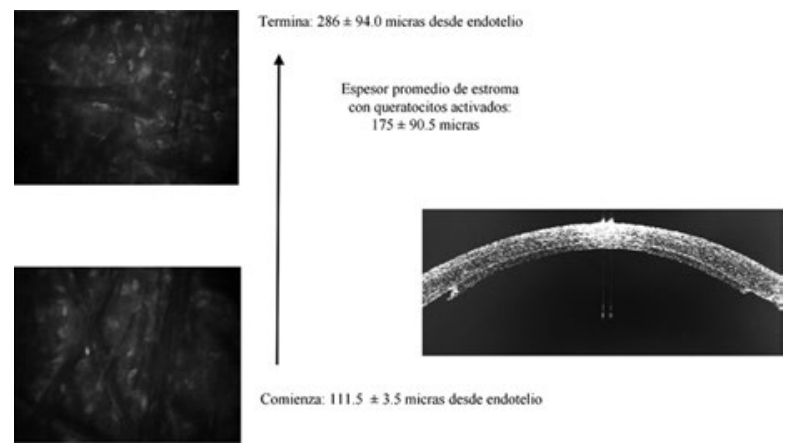

Figura 2. Se ilustra con imágenes de microscopía confocal (izquierda; $340 \times 255 \mu \mathrm{m}$ ) la profundidad a la que empiezan y terminan de observarse los pliegues en el estroma corneal, así como el promedio de espesor de este, con presencia de pliegues; la flecha y la imagen de tomografía de coherencia óptica (derecha) muestran cómo las mediciones se hicieron desde el endotelio hacia el epitelio de la córnea.
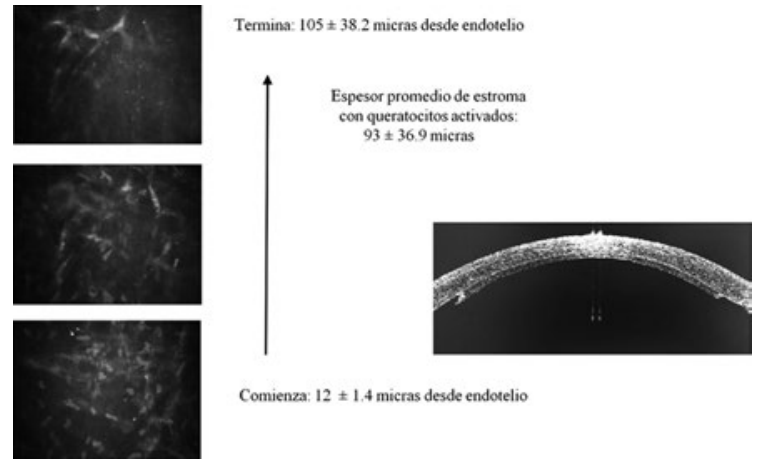

Comienza: $12 \pm 1.4$ micras desde endotelio

Figura 3. Se ilustra con imágenes de microscopía confocal (izquierda) $(340 \times 255 \mu \mathrm{m})$ la profundidad a la que empieza y termina de observarse la presencia de activación de queratocitos en el estroma corneal, así como el promedio de espesor de este, con presencia de activación de Queratocitos; la flecha y la imagen de tomografía de coherencia óptica (derecha) muestran cómo las mediciones se hicieron desde el endotelio hacia el epitelio de la córnea.

Estudios previos de microscopía confocal en pacientes operados de DSAEK reportan la presencia de «niebla» en la interface donador-receptor, así como la presencia de partículas en esta interface similares a las encontradas en cirugía refractiva ${ }^{6-8}$. Prasher, et al. ${ }^{9}$ también reportaron la presencia de partículas en la interface donador-receptor a los 6 meses del posoperatorio, así como activación de queratocitos en el estroma anterior, en contraste con el presente estudio, en el que se encontró activación de queratocitos en el estroma donador, con la diferencia de que nosotros realizamos la microscopía confocal entre las 4 y las 7 semanas del posoperatorio. La activación de queratocitos se ha reportado mediante microscopía confocal en el posoperatorio de todas las técnicas que presentan una reacción cicatricial del estroma de la córnea, como en cirugía refractiva en todas sus variedades $8,10-14$. También se ha reportado activación de queratocitos en el caso de los procedimientos físicos, como el cross-linking ${ }^{15,16}$. La profundidad en el estroma corneal de la activación de los queratocitos, así como su permanencia, varía dependiendo de los distintos procedimientos.

La presencia de partículas en la interface ha sido un hallazgo constante mediante microscopía confocal en todas las técnicas quirúrgicas en la que se genera una interface en el estroma de la córnea, como es el caso la cirugía de LASIK (Laser Assisted In Situ Keratomileusis) $)^{8,10,17}$, independientemente del uso de microqueratomo, o del láser de femtosegundos ${ }^{12}$, así como en la queratoplastia lamelar profunda ${ }^{18}$.

Por su parte, los pliegues en el estroma de la córnea también se han reportado con frecuencia en estudios mediante microscopía confocal en el posoperatorio de cirugías corneales que involucran la presencia de una interface en el estroma de la córnea, como la cirugía de $\operatorname{LASIK}^{17,19}$ y la queratoplastia lamelar profunda ${ }^{18,20}$.

\section{Conclusiones}

El presente estudio se enfocó completamente en los hallazgos cicatriciales tempranos mediante microscopía confocal en pacientes posoperados de trasplante endotelial mediante la técnica de DSAEK, lo cual mostró tanto actividad temprana de queratocitos como la presencia de partículas en la interface donador-receptor y pliegues en el estroma corneal. Los resultados clínicos no fueron el propósito de este estudio.

\section{Responsabilidades éticas}

Protección de personas y animales. Los autores declaran que para esta investigación no se han 
realizado experimentos en seres humanos ni en animales.

Confidencialidad de los datos. Los autores declaran que han seguido los protocolos de su centro de trabajo sobre la publicación de datos de pacientes.

Derecho a la privacidad y consentimiento informado. Los autores declaran que en este artículo no aparecen datos de pacientes.

\section{Conflicto de intereses}

Ningún autor presenta ningún tipo de conflicto de intereses en el presente artículo.

\section{Financiamiento}

El financiamiento del presente estudio fue interno por parte de la institución de afiliación: Departamento de Córnea y Cirugía Refractiva, Asociación para Evitar la Ceguera en México, Hospital Luis Sánchez Bulnes, Universidad Nacional Autónoma de México.

\section{Bibliografía}

1. Koenig SB, Covert DJ, Dupps WJ Jr., Meisler DM. Visual acuity, refractive error, and endothelial cell density six months after Descemet stripping and automated endothelial keratoplasty (DSAEK). Cornea. 2007; 26:670-4.

2. Cursiefen C, Kruse FE. Descemet's stripping with automated endothelial keratoplasty (DSAEK). Ophthalmologe. 2008;105:183-90, 192.

3. Covert DJ, Koenig SB. Descemet stripping and automated endothelial keratoplasty (DSAEK) in eyes with failed penetrating keratoplasty. Cornea. 2007;26:692-6.

4. Melles GR. Posterior lamellar keratoplasty: DLEK to DSEK to DMEK. Cornea. 2006;25:879-81.
5. Bachmann BO, Pogorelov P, Kruse FE, Cursiefen C. Patient satisfaction after posterior lamellar keratoplasty (DSAEK). Klin Monbl Augenheilkd. 2008; 225:577-81.

6. Kobayashi A, Mawatari Y, Yokogawa H, Sugiyama K. In vivo laser confocal microscopy after descemet stripping with automated endothelial keratoplasty. Am J Ophthalmol. 2008;145:977-85.

7. Ferrari G, Reichegger V, Ludergnani L, Delfini E, Macaluso C. In vivo evaluation of DSAEK interface with scanning-laser confocal microscopy. BMC Ophthalmol. 2012;12:32.

8. Vesaluoma M, Perez-Santonja J, Petroll WM, Linna T, Alio J, Tervo T. Corneal stromal changes induced by myopic LASIK. Invest Ophthalmol Vis Sci. 2000;41:369-76.

9. Prasher P, Muftuoglu O, Bowman RW, McCulley JP, Petroll WM, Cavanagh HD, et al. Tandem scanning confocal microscopy of cornea after descemet stripping automated endothelial keratoplasty. Eye Contact Lens. 2009;35:196-202.

10. Mitooka K, Ramirez M, Maguire LJ, Erie JC, Patel SV, McLaren JW, et al. Keratocyte density of central human cornea after laser in situ keratomileusis. Am J Ophthalmol. 2002;133:307-14.

11. Ramírez M, Hernández-Quintela E, Naranjo-Tackman R. Hallazgos estromales in vivo en pacientes operados de PRK con el uso de mitomicina-C. Rev Mex Oftalmol. 2009;83:206-8.

12. Ramírez M, Hernández-Quintela E, Naranjo-Tackman R. A comparative confocal microscopy analysis after LASIK with the IntraLase femtosecond laser vs Hansatome microkeratome. J Refract Surg. 2007;23:305-7.

13. Ramírez M, Hernández-Quintela E, Naranjo-Tackman R. Epi-LASIK: a confocal microscopy analysis of the corneal epithelium and anterior stroma. Ophthalmic Surg Lasers Imaging. 2012;43:319-22.

14. Erie JC, Patel SV, McLaren JW, Maguire LJ, Ramirez M, Bourne WM. Keratocyte density in vivo after photorefractive keratectomy in humans. Trans Am Ophthalmol Soc. 1999;97:221-36; discussion 236-40.

15. Dhaliwal JS, Kaufman SC. Corneal collagen cross-linking: a confocal, electron, and light microscopy study of eye bank corneas. Cornea. 2009; 28:62-7.

16. Ramírez M, Hernández-Quintela E, Naranjo-Tackman R. Early confocal microscopy findings after cross-linking treatment. Arch Soc Esp Oftalmol. 2013;88:179-83.

17. Ramírez M, Hernández-Quintela E, Sánchez-Huerta V, Naranjo-Tackman R. Confocal microscopy of corneal flap microfolds after LASIK. J Refract Surg. 2006;22:155-8.

18. Marchini G, Mastropasqua L, Pedrotti E, Nubile M, Ciancaglini M, Sbabo A. Deep lamellar keratoplasty by intracorneal dissection: a prospective clinical and confocal microscopic study. Ophthalmology. 2006;113:1289-300.

19. Carpel EF, Carlson KH, Shannon S. Fine lattice lines on the corneal surface after laser in situ keratomileusis (LASIK). Am J Ophthalmol. 2000;129:379-80.

20. Ramírez M, Naranjo-Tackman R. Comparación postoperatoria mediante microscopia confocal de queratoplastía lamelar profunda realizada con dos técnicas quirúrgicas: disección por burbuja de aire vs láser de femtosegundos. Rev Mex Oftalmol. 2008;82:34-7. 